\title{
Concerns of Primary Care Clinicians Practicing in an Integrated Health System: a Qualitative Study
}

\author{
Ekaterina Anderson, $\mathrm{PhD}^{7}$ (D) , Amanda K. Solch, MSW ${ }^{7}$, B. Graeme Fincke, $M D^{7,2}$, \\ Mark Meterko, $P h D^{3,3}$, Jolie B. Wormwood, $P h D^{7,4}$, and Varsha G. Vimalananda, \\ $\mathrm{MD}, \mathrm{MPH}^{1,5}$
}

\begin{abstract}
${ }^{1}$ Center for Healthcare Organization and Implementation Research, Bedford VA Medical Center, Bedford, MA, USA; ${ }^{2}$ Boston University School of Public Health, Boston, MA, USA; ${ }^{3}$ VHA Office of Reporting, Analytics, Performance, Improvement and Deployment (RAPID), Bedford, MA, USA;

${ }^{4}$ University of New Hampshire, Durham, $\mathrm{NH}$, USA; ${ }^{5}$ Boston University School of Medicine, Boston, MA, USA.
\end{abstract}

BACKGROUND: Clinician well-being is a major priority for healthcare organizations. However, the impact of workplace environment on clinicians' well-being is poorly understood. Integrated health systems are a particularly relevant type of practice environment to focus on, given the increasing rates of practice consolidation and integration.

OBJECTIVE: To improve understanding of the concerns of primary care clinicians (PCCs) practicing in an integrated health system.

DESIGN: We analyzed free-text comment box responses offered on a national survey about care coordination by 555 PCCs in the Veterans Health Administration, one of the largest integrated health systems in the USA.

PARTICIPANTS: A total of 555 PCCs who left free-text comments on a national survey of care coordination in the VHA (30\% out of 1862 eligible respondents). Demographics and coordination scale scores were similar between respondents who left comments vs. those who did not.

APPROACH: The data were coded and analyzed in line with the grounded theory approach. Key themes were identified by team consensus and illustrative quotations were chosen to illustrate each theme.

KEY RESULTS: VHA PCCs described some pressures shared across practice environments, such as prohibitive administrative burden, but also reported several concerns particular to integrated settings, including "dumping" by specialists and moral distress related to a concern for patients. Frustrations due to several aspects of responsibility around referrals may be unique to integrated health systems with salaried clinicians and/or where specialists have the ability to reject referrals.

CONCLUSION: PCCs in integrated health systems feel many of the same pressures as their counterparts in nonintegrated settings, but they are also confronted with unique stressors related to these systems' organizational features that restrict clinicians' autonomy. An understanding of these concerns can guide efforts to improve the well-being of PCCs

Electronic supplementary material The online version of this article (https://doi.org/10.1007/s11606-020-06193-3) contains supplementary material which is available to authorized users.

Received January 8, 2020

Revised May 8, 2020

Accepted August 27, 2020

Published online September 11, 2020 in existing integrated health systems, as well as in practices on their way to integration.

KEY WORDS: Veterans; primary care; integrated health systems; clinician well-being.

J Gen Intern Med 35(11):3218-26

DOI: $10.1007 / \mathrm{s} 11606-020-06193-3$

(c) Society of General Internal Medicine (This is a U.S. government work and not under copyright protection in the U.S.; foreign copyright protection may apply) 2020

\section{INTRODUCTION}

Stressed and dissatisfied clinicians are more likely to be depressed, provide worse quality of care, cut down their hours, or leave medicine altogether, exacerbating existing workforce shortages. ${ }^{1-4}$ In recent years, clinicians and policymakers have rallied around the Quadruple Aim, which adds clinician well-being to the Institute for Healthcare Improvement Triple Aim for healthcare quality (population health, healthcare costs, and patient experience). ${ }^{5,}{ }^{6}$ Research suggests that clinician well-being is negatively affected by organizational factors, such as excessive workload, insufficient control over work processes, heavy clerical burdens, misalignment with leadership's values, inadequate support and resources, and lack of collaborative working relationships. ${ }^{7-16}$ However, as a recent literature review highlights, the effect of organizational factors associated with different types of practice environments is poorly understood. ${ }^{10}$

Clinician well-being in integrated health systems (or integrated delivery systems) is especially relevant given the accelerating trend toward practice consolidation and integration. ${ }^{17}$ We use the term "clinicians" to describe physicians and advanced practice providers, including nurse practitioners and physician assistants, in primary care ("primary care clinicians" or "PCCs") and specialty care ("specialists"). Few direct comparisons of factors that affect the well-being of clinicians in integrated vs. nonintegrated settings have been published, and findings are mixed. One study found that physicians in integrated systems report higher levels of personal accomplishment and lower levels of depersonalization than their counterparts in minimally integrated settings. ${ }^{18}$ In another survey, primary care physicians who work 
in settings with an organizational emphasis on care quality (rather than productivity) also report a greater sense of satisfaction, ${ }^{12}$ which suggests that clinicians in large, integrated systems may be at an advantage, given that these systems generally possess a greater capacity to pursue quality improvement initiatives. ${ }^{19,}{ }^{20}$ However, abundant evidence also suggests that clinicians who perceive themselves as lacking control over clinical and workplace issues may experience higher dissatisfaction and burnout rates. $^{8,13,21,22}$ It is possible, therefore, that a relative lack of autonomy in integrated settings, and especially in highly integrated systems, may have a deleterious effect on clinicians' well-being. Indeed, several studies have found a greater sense of control over the work environment to be associated with greater job satisfaction and lower burnout rates. ${ }^{8,23}$ In sum, research is still in its early stages, and a lot remains to be learned about the impact of common organizational characteristics of integrated systems on clinician well-being.

A better understanding of clinician experiences in integrated health systems would inform efforts to ameliorate clinician distress both in the established systems and in practices on their way to integration. ${ }^{24,}{ }^{25}$ In this paper, we address this gap by turning the spotlight to the experiences of a nation-wide sample of primary care clinicians (PCCs) in one of the largest integrated systems in the USA, Veterans Health Administration (VHA). PCCs are a professional group of particular concern, given their alarmingly high burnout rates. ${ }^{26-29} \mathrm{Be}-$ cause VHA has certain distinguishing characteristics that set it apart, our findings may have greatest relevance to PCCs who practice in fully integrated systems with salaried clinicians and/or where specialists have the ability to reject referrals. However, VHA also has many features in common with other large integrated systems, such as Mayo Clinic, Kaiser Permanente, and Intermountain Health System. These include an overarching organizational structure, a shared electronic health record, and a focus on standardization, quality improvement, and rigorous documentation standards. ${ }^{30-35}$ Several of these organizational features impose limitations on clinicians' autonomy, which, in turn, may have an impact on their work life and well-being. ${ }^{36,}{ }^{3726-29}$ Therefore, many insights presented below have a broader relevance to clinicians in other integrated health systems. ${ }^{38}$

\section{METHODS}

The study setting is the Veterans Health Administration (VHA), a large integrated health system. VHA employs over 300,000 healthcare professionals and provides care to more than $9,000,000$ patients at 1255 facilities. ${ }^{39}$

The Coordination of Specialty Care-Primary Care Provider Survey (CSC-PCP) was administered online in April 2018 to 7979 VHA PCCs. ${ }^{40}$ Originally titled CSC-PCC (Coordination of Specialty Care-Primary Care Clinician), the survey was renamed by the survey study PI prior to final acceptance of the related manuscript. We retain the term PCC in this manuscript to avoid hierarchical connotations associated with the dichotomy of "PCP/specialist."

The CSC-PCP survey explored PCC perspectives on relationships, roles and responsibilities, data transfer, and communication with respect to specialty care providers, as part of a larger study of care coordination between PCCs and specialists in VHA (see Appendix 1 for additional details on the survey content). ${ }^{38,41,42}$ All VHA PCCs, i.e., physicians and advanced practice providers (including nurse practitioners and physician assistants), were eligible to participate. Nonrespondents received a total of 3 reminders at 4-5-day intervals.

After 23 PCC respondents contacted the research team with additional thoughts to share, we appended a free-text comment box to the survey, phrased in the following way: "Please use this space to voice your opinion on any other issues related to coordination with specialty care that may not have been addressed in the survey. There is no word or character limit on your comments."

Ninety-five respondents accessed and filled out the survey before the comment box was added. The modified version of the survey (with the free-text comment box) was accessed by 1957 respondents. Of the 1862 who were eligible to complete the survey after responding to screener questions, 555 (30\%) left a response in the comment box, including 328 physicians and 203 advanced practice providers (see Table 1). The overall survey response rate (counting respondents who participated before and after the addition of the comment box) was $23 \%$ $(N=1862)$, consistent with results from other VHA online clinician surveys. ${ }^{38,43,44}$ The comments ranged in length from a sentence to several paragraphs and were marked with a heightened emotional tone. Although the survey was focused on care coordination, it had opened a path for VHA PCC respondents to talk about a much wider spectrum of issues.

Table 1 Demographic Characteristics of Survey Responders

\begin{tabular}{lcc}
\hline \hline & $\begin{array}{l}\text { Comment box } \\
\text { responders }(\boldsymbol{N = 5 5 5})\end{array}$ & $\begin{array}{l}\text { Comment box non- } \\
\text { responders }(\boldsymbol{N}=\mathbf{1 3 0 7})\end{array}$ \\
\hline $\begin{array}{l}\text { Degree } \\
\text { MD or }\end{array}$ & $328(59.1 \%)$ & $728(55.7 \%)$ \\
DO & $153(27.6 \%)$ & $342(26.2 \%)$ \\
NP & $19(3.4 \%)$ & $76(5.8 \%)$ \\
PA & $31(5.6 \%)$ & $97(7.4 \%)$ \\
Other & $24(4.3 \%)$ & $64(4.9 \%)$ \\
Missing & & $503(38.5 \%)$ \\
Location & $207(37.3 \%)$ & $582(44.5 \%)$ \\
VAMC* & $230(41.4 \%)$ & $127(9.7 \%)$ \\
CBOC $\dagger$ & $81(14.6 \%)$ & $31(2.4 \%)$ \\
HBPC ${ }^{\dagger}$ & $13(2.3 \%)$ & $64(4.9 \%)$ \\
Other & $24(4.3 \%)$ & $478(36.6 \%)$ \\
Missing & & $266(20.3 \%)$ \\
Age & $195(35.1 \%)$ & $563(43.1 \%)$ \\
$\geq 50$ years & $130(23.4 \%)$ & \\
<50 & $230(41.4 \%)$ & \\
Missing & & \\
\hline
\end{tabular}

*VA Medical Center

†Community-Based Outpatient Clinic (VA outpatient clinic affiliated but not physically co-located with a VA Medical Center)

tHome-Based Primary Care (in-home support for Veterans with complex conditions who may have difficulty with regular clinic visits) 
Demographics and scores on multi-item scales measuring six domains of coordination were similar between respondents who left comments vs. those who did not (see Tables 1 and 2).

The research team included six health services researchers with backgrounds in anthropology (EA), social work (AS), internal medicine and infectious diseases (GF), survey research (MM), psychology (JW), and endocrinology and public health (VV). Data analysis was led by EA, an experienced qualitative researcher, with participation by AS and VV who each have experience in qualitative research methods. Our analytical approach, informed by grounded theory, ${ }^{45}$ prioritized codes and themes emerging from the data over a priori constructs. We also followed methodological precedents for rigorous qualitative analysis of free-text survey comments. ${ }^{46-}$ ${ }^{49}$ After three team members (EA, AS, VV) coded a sample of 35 comment box responses independently, an initial codebook was created through discussion and consensus. It was refined iteratively over several rounds of independent and collective coding, as coders introduced new codes, created sub-codes,

Table 2 Mean Scale Scores for Survey Responders $(N=1862)$

\begin{tabular}{|c|c|c|}
\hline Question & $\begin{array}{l}\text { Comment box } \\
\text { responders } \\
(N=555)\end{array}$ & $\begin{array}{l}\text { Comment box non- } \\
\text { responders } \\
(N=1307)\end{array}$ \\
\hline \multicolumn{3}{|l|}{ Care coordination scales ${ }^{\S}$} \\
\hline $\begin{array}{l}\text { Relationships and } \\
\text { collaboration }\end{array}$ & $\begin{array}{l}5.25(365)(\mathrm{Std}= \\
1.15)\end{array}$ & $\begin{array}{l}5.21(819)(\mathrm{Std}= \\
1.15)\end{array}$ \\
\hline Communication & $\begin{array}{l}4.96(295)(\mathrm{Std}= \\
1.51)\end{array}$ & $\begin{array}{l}4.94(693)(\mathrm{Std}= \\
1.45)\end{array}$ \\
\hline Role agreement & $\begin{array}{l}5.55(418)(\mathrm{Std}= \\
1.04)\end{array}$ & $\begin{array}{l}5.58(929)(\mathrm{Std}= \\
1.04)\end{array}$ \\
\hline Data transfer & $\begin{array}{l}6.04(355)(\mathrm{Std}= \\
1.05)\end{array}$ & $\begin{array}{l}6.07(794)(\mathrm{Std}= \\
0.98)\end{array}$ \\
\hline Role clarity & $\begin{array}{l}5.05(N=361) \\
(\mathrm{Std}=1.29)\end{array}$ & $\begin{array}{l}4.97(826)(\mathrm{Std}= \\
1.27)\end{array}$ \\
\hline Making referrals & $\begin{array}{l}3.50(429)(\mathrm{Std}= \\
0.83)\end{array}$ & $\begin{array}{l}3.43(969)(\mathrm{Std}= \\
0.90)\end{array}$ \\
\hline \multicolumn{3}{|l|}{ Satisfaction scales } \\
\hline Satisfied with job & $\begin{array}{l}3.58(345)(\mathrm{Std}= \\
1.09)\end{array}$ & $\begin{array}{l}3.57(777)(\mathrm{Std}= \\
1.07)\end{array}$ \\
\hline $\begin{array}{l}\text { Satisfied with } \\
\text { coworkers }\end{array}$ & $\begin{array}{l}3.96(345)(\mathrm{Std}= \\
1.00)\end{array}$ & $\begin{array}{l}3.99(778)(\mathrm{Std}= \\
0.97)\end{array}$ \\
\hline $\begin{array}{l}\text { Satisfied with } \\
\text { organization }\end{array}$ & $\begin{array}{l}3.22(345)(\mathrm{Std}= \\
1.11)\end{array}$ & $\begin{array}{l}3.22(779)(\mathrm{Std}= \\
1.11)\end{array}$ \\
\hline \multicolumn{3}{|l|}{ Burnout scales ${ }^{\mathrm{T}}$} \\
\hline Feeling burned out & $\begin{array}{l}4.32(343)(\mathrm{Std}= \\
1.86)\end{array}$ & $\begin{array}{l}4.39(776)(\mathrm{Std}= \\
1.79)\end{array}$ \\
\hline $\begin{array}{l}\text { Feeling cynical/ } \\
\text { detached }\end{array}$ & $\begin{array}{l}3.44(343)(\mathrm{Std}= \\
2.10)\end{array}$ & $\begin{array}{l}3.64(775)(\mathrm{Std}= \\
2.07)\end{array}$ \\
\hline Feeling accomplished & $\begin{array}{l}5.49(342)(\mathrm{Std}= \\
1.63)\end{array}$ & $\begin{array}{l}5.57(777)(\mathrm{Std}= \\
1.56)\end{array}$ \\
\hline
\end{tabular}

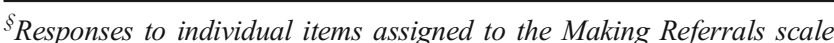
are on a 5-point frequency scale from 1 (Never) to 5 (Always). Responses to items assigned to the other scales are on a 7-point frequency scale from 1 (Never) to 7 (Always). All items ask about experiences in the last the last 3 months. Scale scores are calculated using data from respondents whose data are non-missing on at least half of the items in that scale. The scales are scored as the simple average of the scores for the items assigned to that scale and have a theoretical range from 1 to 5 (Making Referrals scale) or 1-7 (for the rest of the scales)

'Satisfaction item response scales: 1-very dissatisfied, 2-dissatisfied, 3-neutral, 4-satisfied, 5-very satisfied

"Burnout item response scales: 1-never, 2-few times a year, 3-once a month or less, 4-few times a month, 5-once a week, 6-few times a week, 7-every day clarified definitions of individual codes, and changed hierarchical relationships between codes. After finalizing the codebook, the same three team members continued to code the comments independently in NVivo 12 software (QSR International), meeting regularly for discussion. All 555 comments were coded, with theoretical saturation reached in the process. The full team then generated key themes through consensus and selected representative quotations to illustrate each theme. The study was approved by the Bedford VA Institutional Review Board. Additional details about the data analysis methodology are included in Appendix 1.

\section{RESULTS}

We identified four prominent themes across PCC comments: (1) struggle over referrals, (2) "dumping" by specialists, (3) administrative burden, and (4) moral distress. Quotations are followed by the respondents' study ID numbers. For additional exemplary quotations, see Appendix 2.

\section{Struggle over Referrals}

In the VHA, referrals ("consults") are sent to specialty services through the shared EHR. To promote efficient utilization of specialty care in the VHA, specialty services review the referrals and either schedule them, decline them, or request additional information. ${ }^{50}$ In our survey, comments about specialty referrals were common. In contrast to the collegial connotation of the term "care coordination," several PCCs use the metaphors of struggle, resistance, and game-like competition to describe their experiences, frequently portraying specialists as unsympathetic and uncooperative:

It is a constant battle to make sure patients are getting follow up appointments... (123). The specialty services... treat this consult process like a game. They [nitpick] \& find the slightest miniscule, typically inexcusable and ridiculous reason to cancel your consult request, $\&$ then have the audacity to comment that you should order a new consult (455).

In this largely contentious context, some PCCs perceive specialists who refuse to accept referrals as, in effect, preventing referring providers from exercising their clinical judgment:

The ability of the specialty clinics to cancel consults requested by primary care providers without seeing or evaluating the patient is inappropriate. When a consult has been placed, it serves as an indicator that the PCP has reached the limits of their scope of care and $<$ is $>$ requesting specialty guidance (76).

Some PCCs also opine that specialists reject referrals in an improper, disrespectful fashion: 
The specialists often treat consulting physicians in a condescending manner. <...> Snippy or sarcastic comments back on a consult before the consult is discontinued are unprofessional and unwarranted (326).

E-consults (electronic consultations) are an asynchronous consultation modality used in the VHA and some other health systems to expedite care by obtaining specialist advice without a face-to-face referral. These are described by some PCCs as a way for specialists to avoid seeing patients:

Some specialists too freely convert consult orders into E-consult orders in inappropriate situations, in what appears to be an attempt to limit the number of patients who are scheduled for face-to-face visits in their clinic (52).

Similarly, service agreements and referral templates are viewed by some PCCs as tools wielded by specialists to restrict, rather than facilitate, PCCs' ability to request referrals:

The consultants on the most part HIDE behind their service agreements. Labs and imaging that is not avail[able] to any of my vets could get completed at the <consultant's $>$ facility same day as seen and the consultants REFUSE and cancel consult after consult (253).

Interestingly, some PCCs attribute the contentious nature of specialty care referrals to organizational features that discourage specialists from accepting referrals, in contrast to the private sector where specialists are incentivized to do so:

New to VA from private sector. Amazed at how easily and frequently specialists reject referrals $<\ldots .$. . Sometimes have to place referral requests multiple times. Not so in the private sector where specialists rely on PCP for 'business' and referrals (355).

While some PCCs did report positive experiences, referrals were generally portrayed as a source of contention, attributed to the specialists' unprofessionalism and gatekeeping or to structural disincentives.

\section{"Dumping" by Specialists}

A related concern expressed by many respondents involves the perceived "dumping" of tasks by specialists. Some PCCs report that specialists impose an unreasonable volume of workup and testing to be completed in primary care prior to specialty care appointments:

The amount of things dumped on primary care is mindblowing. When trying to place consults, the services want a plethora of things done first to which we have no access (229).

Similarly, the conversion of face-to-face referrals to econsults is also described by some as dumping:

They flip all the consults to [e-consults] and... throw all the work back on primary care to do extensive workups that are beyond our training or comfort level. There have been numerous complaints but nothing is done. Although primary care is the backbone of the VA we are treated like dirt to do the specialists bidding (195).

Many PCCs also describe a growing burden of tasks being dumped on them that they perceive as being within the purview of specialists, including requesting tests, ordering medication, and scheduling follow-up specialty care appointments:

[Specialists] have no sense of responsibility towards the patients that are referred to them. Everything is dumped on Primary care $\langle\ldots\rangle$ follow up appts not scheduled, meds prescribed by them not refilled, despite [EHR] reminders to set [follow up] for patients, no action taken (235).

For numerous PCCs in our dataset, this prohibitive workload spills outside of the normal working hours, leaving them feeling overwhelmed:

I routinely work an extra 20 hours of unpaid overtime each week, after hours and from home, in order to do the tasks for my patients that are left undone by specialists and other healthcare staff members (52).

It is not only the heavy workload that some PCCs deem problematic, but the growing share of tasks perceived as lowlevel or clerical:

Primary Care spend over half their time doing computer work consultations rather [than] providing quality care to veterans (105).

Some respondents also report that they feel like specialists' subordinates rather than equal partners:

Specialty service providers at our facility do not utilize Primary Care Providers as partners in co-management of patient care but rather... as CLERKS to do their clerical work (443).

In sum, respondents' concerns about dumping largely derive from their perception that many tests related to initial referrals and ongoing care should be the responsibility of 
specialists rather than delegated to PCCs. In other words, some PCCs see specialists as unwilling to equitably share ownership for patient care.

\section{Administrative Burden}

In addition to their frustration with workload shifting by specialists, PCCs expressed concerns related to the growing administrative burden, more generally. The lack of protected time to address administrative tasks came up repeatedly as a prominent, system-level issue:

No one in this entire... system $<\ldots>$ have any clue about how much work is piled on PCP. $<\ldots>$ No administrative time is given for coordination, paperwork, phone calls, view alerts. We are given 30 minutes each day. $\langle\ldots\rangle$ You are burning out your PCPs or not paying them enough for the amount of work expected. Metrics are not capturing true workload of all paperwork (295).

Some of the complaints highlighted the disruptive effect of EHR alerts and reminders on clinical workflows and patientprovider rapport:

The reminders often pop up without us being trained on how to use them and when you see a patient with lots of problems and only $1 / 2$ hour in which to see them, and the reminders take up 10-15 minutes (esp. if a new pt.) the pts. are very mad and blame me, the doctor stuck in the middle of meeting VACO’s never ending metrics!!!!! (505).

Other PCCs lamented an erosion of their professional identity caused by the rising documentation workload:

I worked in private practice where I actually did doctoring. Here... I do very little doctoring, mostly I'm a secretary, typist, and I have no authority. ${ }^{78}$

As one respondent describes, administrative burden remains stressful even when the clinical appointment workload is reduced:

I used to be able to see 17-21 veterans per day and not be stressed. I now am very stressed to see 8 . I spend $90 \%$ of my day entering data into the computer. This is not what I trained for (499).In sum, respondents describe an exhausting workload and a workflow that prioritizes clerical tasks over clinical care, giving rise to feelings of disrespect and erosion of professional identity.

\section{Moral Distress}

Finally, many of the PCCs express a sense of moral distress related to the perceived impact of the organizational issues described in preceding sections on patients and patient care. Some of these concerns relate to the perceived lack of timeliness in accessing specialty care:

[T]oo often patients are not seen timely. The reason for consult is not addressed and sometimes outright denial to see patient (from certain departments) (376).

Some respondents also describe themselves as "stuck" in the middle between uncooperative specialists and angry, frustrated patients who are unable to obtain a face-to-face appointment:

Our challenge here is that some specialties are quick to decline consults or put too many pre-requisites before they accept a patient and we have to face the frustrations of the veterans when they are expecting to be seen by a specialist (97).

Other PCCs feel that their own ability to provide highquality care is compromised by the workload:

I could see more pt's easily. Provide more and better care, if I were not spending so much time in clerical activities... Is it really effective use of employee who has spent 7 years after college and 11 years after high school to spend typing in meds and re-submitting consults that should not have been discontinued <...>?. ${ }^{44}$

Although the original survey asked respondents to focus on experiences with care coordination in the VHA, some of the comments were related to coordinating care with "community" (non-VHA) providers. At the time of the survey, the VHA was implementing the Veterans' Choice Act, intended to facilitate the access of Veterans facing long wait times and/ or travel distances to care in the community (replaced in June 2019 by the VA MISSION Act with a similar focus). Amidst these policy changes, some PCCs express concern that patients do not receive community care referrals as promptly and frequently as needed:

The problem is coordinating care with specialty care for patients going outside the VA system for care. $<\ldots>$ I have seen delays related to timely referrals outside the VA causing patient harm. It is indefensible, inexcusable, and immoral (293).

Others, by contrast, are worried about the effects of the growing access to community care, perceived as subpar, on patients. One particularly critical respondent wrote:

I can say [WITHOUT] HESITATION that removing specialties from the VA and placing that care in the hands of outside providers would be a DISASTER. Outside physicians resist treating VA patients NOW 
because we have a complex population with numerous co-morbidities. <...> Please, I implore those in power to leave the specialties within the VA (436).

Overall, many respondents express a sense of moral distress due to their perception that they are too often unable to deliver or arrange for the care that they think they patients should have.

\section{DISCUSSION}

Through an analysis of free-text survey responses from a sample of VHA PCCs, we identified a number of key concerns, reflecting a mix of pressures experienced by PCCs across practice settings and stressors that may be particular to integrated systems.

PCCs in our sample report struggling with a heavy administrative burden that is increasingly marginalizing direct patient care. The growing rates of clinician stress, dissatisfaction, and burnout due to time pressures, heavy documentation burden, loss of professional autonomy, and decreased control over practice environment are not unique to the VHA and have been reported widely. ${ }^{51-53} \mathrm{~A}$ general sense of being undervalued, as evidenced by salary inequity, perceived lack of prestige, and even the language used to refer to clinicians (i.e., some are "special"), is common among primary care clinicians and exacerbates dissatisfaction. ${ }^{54-57}$ These shared stressors can be addressed through such measures as adopting EHR systems designed with clinicians' needs in mind, ${ }^{58,59} \mathrm{a}$ wider use of clinical scribes, ${ }^{60,61}$ implementing team-based care, ${ }^{9,} 62,63$ and providing protected administrative time. ${ }^{64}$ To counteract the erosion of clinicians' professional identity, stakeholders might create and expand opportunities for PCCs to pursue professional development and nurture relationships with other clinicians.

Other themes identified in our study appear to be more specific to practice in integrated health systems. One phenomenon that may be unique to integrated health systems is the perceived extent of "dumping." Qualitative studies of PCC experiences in the UK's National Health Service have identified dumping by specialists as a grievance, ${ }^{65,} 66$ and a comparative study of 16 US health systems with shared electronic referral and/or consultation systems reported that some PCCs perceive a shared EHR as facilitating the transfer of work tasks by specialists. ${ }^{67}$ It is not surprising that some specialists shift the burden of work (i.e., "dump") onto their PCC colleagues given the ease of delegating tasks through the shared EHR, the often ambiguous organizational division of roles and responsibilities, ${ }^{42}$ the rising productivity pressures, ${ }^{68}$ the lack of financial incentives to see patients, ${ }^{69,70}$ and the lack of quality indicators for specialists. ${ }^{71}$ It is important to look beyond the potential motivation of individual specialists to the structural features of integrated systems that facilitate and motivate dumping. We recommend that stakeholders ensure that the additional workload of PCCs due to work-shifting by specialists is equitably recognized and compensated. Jointly negotiated service agreements would clarify division of responsibilities between specialists and PCCs by promoting a shared understanding of such details as what goes into the consultation request or into the specialist's response note, as well as who should be responsible for carrying out the recommended actions. These agreements could also introduce incentives for specialists to maintain ownership over some categories of patients, thus alleviating the PCC burden and potentially improving patient care quality.

Another finding appears to be most relevant to integrated systems where clinicians are paid a salary and specialists have the ability to reject or convert referrals. Literature on specialty referrals often focuses on the lack of timely and sufficient communication from specialists following the referral, ${ }^{72-74}$ but this issue is less prominent in the context of a shared EHR. Rather, the referral-related complaints in our study were primarily related to the perception of inappropriately rejected or converted referrals. ${ }^{72-74}$ This finding is consistent with those of earlier surveys of VHA PCCs on referral communication. ${ }^{42,}{ }^{50}$ Our study builds on these prior findings by elucidating how PCCs make sense of rejected referrals. Specialists salaried in integrated health systems, unlike their private sector counterparts, do not have an inherent incentive to solicit referrals from PCCs. When PCCs perceive specialists as hostile gatekeepers, this creates an adversarial dynamic between PCCs and specialists that threatens clinician well-being and could ultimately undermine care quality. While the rejection of some referrals may be inevitable, the negative impacts described here could be mitigated by ensuring agreement between services on referral criteria ${ }^{75}$ and incentivizing specialists to provide detailed and respectful justifications for rejecting referral requests. Surveys such as the Coordination of Specialty Care-Primary Care Provider (CSC-PCP) ${ }^{40}$ and the Coordination of Specialty Care-Specialist (CSC-Specialist) ${ }^{38,41}$ can be used to capture both referring and consulting providers' perspectives on the quality of inter-clinician communication and relationships and subsequently guide improvement efforts.

Finally, we identified the theme of moral distress, or the anguish experienced due to perceived inability to act in accordance with one's ethical ideals, ${ }^{76-78}$ in the survey comments. PCCs in some integrated health systems are structurally positioned to act as gatekeepers to care, while also facing gatekeeping behavior by specialists. In this context, PCCs may feel that they are prevented from providing the best care possible due to constraints imposed by the system. Distinctive from burnout, this form of moral distress may be a particularly corrosive unintended consequence of practicing primary care in an integrated health system, but it also reminiscent of the moral distress among clinicians in managed care systems forced to "ration" healthcare on the basis of deservingness ${ }^{79}$ and the dissatisfaction reported by physicians across different 
types of practice environment about payers refusing to cover necessary medical services. ${ }^{16}$

This study has limitations. Most fundamentally, our findings may appear to have limited generalizability beyond the VHA. One of the most distinctive features of the VHA, shared by only some integrated health systems, is the ability of specialists, who are salaried and therefore do not have inherent financial incentives to see patients, to reject referrals. However, all integrated health systems strive to provide efficient care, wherein patients are seen by specialists only as appropriate. ${ }^{35}$ The downside of this mission to avoid unnecessary care is that PCCs, unable to override a referral rejection, may experience this as a slight to their autonomy. Therefore, while we concede that the findings of this study may be most closely applicable to large, fully integrated health systems where providers are salaried and/or specialists have the ability to reject referrals, we contend that they also have a broader relevance to all integrated settings where clinicians' autonomy may be constrained.

Other limitations need to be acknowledged. Our analysis, by design, did not include the perspectives of PCC survey participants who did not leave responses in the comment box or of specialists. However, there were no differences in selfreported burnout, satisfaction, or scores on survey care coordination scales among PCCs who did vs. did not leave comments (Tables 1 and 2). Additionally, we did not discuss any interdisciplinary differences in PCC experiences. Although our analysis did not detect any differences between survey responses left by advanced practice providers vs. their physician counterparts, interdisciplinary differences in PCC experiences do exist ${ }^{14,80-82}$ and warrant closer study. It is also possible that the study underemphasized differences between PCCs at different VHA sites and overlooked some of the issues faced by non-VHA clinicians that are not salient in the VHA context. Finally, because the survey focused on the topic of care coordination, many (although not all) of the identified themes relate to care coordination and/or relationships with specialists, more broadly. These limitations notwithstanding, our analysis, which drew on a large, national data sample and employed rigorous qualitative data analysis procedures, provides insight into many issues that appear to be regularly encountered by PCCs across integrated health systems and some that may be characteristic of primary care settings at large.

\section{CONCLUSION}

VHA PCCs report some experiences that may be shared by their counterparts in non-integrated practice settings, such as a prohibitive workload and a documentation-heavy workflow. Other challenges, including conflicts surrounding specialty care referrals, frustrations with "dumping" of work by specialists, and a specific form of moral distress, seem particular to integrated health systems, especially those with salaried clinicians and/or where specialists have the ability to reject referrals. Integrated health systems and practices in the process of integration would do well to recognize these dangers and adjust their policies to avoid these negative effects among their PCCs.

Corresponding Author: Ekaterina Anderson, PhD; Center for Healthcare Organization and Implementation Research, Bedford VA Medical Center, Bedford, MA, USA (e-mail: ekaterina.anderson@va. gov).

Funding This study was supported by the VHA HSR\&D Career Development Award 5IK2HX002137-02 for Dr. Varsha Vimalananda.

\section{Compliance with Ethical Standards:}

The study was approved by the Bedford VA Institutional Review Board.

Conflict of Interest: The authors declare that they have no conflict of interest.

Disclaimer: The contents of this paper do not represent the views of the US Department of Veterans Affairs or the United States Government.

\section{REFERENCES}

1. Reith TP. Burnout in United States Healthcare Professionals: A Narrative Review. Cureus. 2018;10(12):e3681.

2. Montgomery A, Panagopoulou E, Kehoe I, Valkanos E. Connecting organisational culture and quality of care in the hospital: is job burnout the missing link? J Health Organ Manag. 2011;25(1):108-23.

3. Jourdain G, Chenevert D. Job demands-resources, burnout and intention to leave the nursing profession: a questionnaire survey. Int $\mathrm{J}$ Nurs Stud. 2010;47(6):709-22.

4. Wurm W, Vogel K, Holl A, Ebner C, Bayer D, Mork1 S, et al. DepressionBurnout Overlap in Physicians. PLoS One. 2016;11(3):e0149913.

5. Bodenheimer T, Sinsky C. From triple to quadruple aim: care of the patient requires care of the provider. Ann Fam Med. 2014;12(6):573-6.

6. Sikka R, Morath JM, Leape L. The Quadruple Aim: care, health, cost and meaning in work. BMJ Qual Saf. 2015;24(10):608-10.

7. Leiter MP, Laschinger HKS. Relationships of work and practice environment to professional burnout: testing a causal model. Nursing Research. 2006;55(2):137-46.

8. Freeborn DK. Satisfaction, commitment, and psychological well-being among HMO physicians. West J Med. 2001;174(1):13-8.

9. Willard-Grace $\mathbf{R}$, Hessler $\mathbf{D}$, Rogers $\mathbf{E}$, Dube $\mathbf{K}$, Bodenheimer $\mathbf{T}$, Grumbach K. Team structure and culture are associated with lower burnout in primary care. J Am Board Fam Med. 2014;27(2):229-38.

10. West CP, Dyrbye LN, Shanafelt TD. Physician burnout: contributors, consequences and solutions. J Intern Med. 2018;283(6):516-29.

11. Linzer M, Visser MR, Oort FJ, Smets EM, McMurray JE, de Haes HC, et al. Predicting and preventing physician burnout: results from the United States and the Netherlands. Am J Med. 2001;111(2):170-5.

12. Williams ES, Konrad TR, Linzer M, McMurray J, Pathman DE, Gerrity M, et al. Physician, practice, and patient characteristics related to primary care physician physical and mental health: results from the Physician Worklife Study. Health Serv Res. 2002;37(1):121-43.

13. Rassolian M, Peterson LE, Fang B, Knight HC, Jr., Peabody MR, Baxley EG, et al. Workplace Factors Associated With Burnout of Family Physicians. JAMA Intern Med. 2017;177(7):1036-8.

14. Coplan B, McCall TC, Smith N, Gellert VL, Essary AC. Burnout, job satisfaction, and stress levels of PAs. JAAPA. 2018;31(9):42-6.

15. McHugh MD, Kutney-Lee A, Cimiotti JP, Sloane DM, Aiken LH. Nurses' widespread job dissatisfaction, burnout, and frustration with 
health benefits signal problems for patient care. Health Aff (Millwood). 2011;30(2):202-10.

16. Friedberg MW, Chen PG, Van Busum KR, Aunon F, Pham C, Caloyeras J, et al. Factors Affecting Physician Professional Satisfaction and Their Implications for Patient Care, Health Systems, and Health Policy. Rand Health Q. 2014;3(4):1.

17. Kane CK. Updated data on physician practice arrangements: For the first time, fewer physicians are owners than employees. Policy Research Perspectives. Chicago: American Medical Association; 2019.

18. Zubatsky M, Pettinelli D, Salas J, Davis D. Associations Between Integrated Care Practice and Burnout Factors of Primary Care Physicians. Fam Med. 2018;50(10):770-4.

19. Friedberg MW, Safran DG, Coltin KL, Dresser M, Schneider EC. Readiness for the Patient-Centered Medical Home: structural capabilities of Massachusetts primary care practices. J Gen Intern Med. 2009;24(2): 162-9.

20. Audet AM, Doty MM, Shamasdin J, Schoenbaum SC. Measure, learn, and improve: physicians' involvement in quality improvement. Health Aff (Millwood). 2005;24(3):843-53.

21. Edwards ST, Marino M, Balasubramanian BA, Solberg LI, Valenzuela S, Springer R, et al. Burnout Among Physicians, Advanced Practice Clinicians and Staff in Smaller Primary Care Practices. J Gen Intern Med. 2018;33(12):2138-46

22. Kimo Takayesu J, Ramoska EA, Clark TR, Hansoti B, Dougherty J, Freeman W, et al. Factors Associated With Burnout During Emergency Medicine Residency. Acad Emerg Med. 2014;9:1031-5.

23. Gregory S. Burnout Among Primary Care Physicians: A Test of the Areas of Worklife Model. Journal of Healthcare Management. 2015;60(2):13348

24. Lesser CS, Ginsburg PB. Update on the nation's health care system: 1997-1999. Health Aff (Millwood). 2000;19(6):206-16.

25. Muhlestein DB, Smith NJ. Physician Consolidation: Rapid Movement From Small To Large Group Practices, 2013-15. Health Aff (Millwood). 2016;35(9):1638-42.

26. Soler JK, Yaman H, Esteva M, Dobbs F, Asenova RS, Katic M, et al Burnout in European family doctors: the EGPRN study. Fam Pract. 2008;25(4):245-65.

27. Schaufeli W, Maassen G, Bakker A, Sixma H. Stability and change in burnout: A 10-year follow-up study among primary care physicians. Journal of Occupational and Organizational Psychology. 2011;84(2):24867.

28. Linzer M, Manwell LB, Williams ES, Bobula JA, Brown RL, Varkey AB, et al. Working conditions in primary care: physician reactions and care quality. Ann Intern Med. 2009;151(1):28-36, W6-9.

29. Rabatin J, Williams E, Baier Manwell L, Schwartz MD, Brown RL, Linzer M. Predictors and Outcomes of Burnout in Primary Care Physicians. J Prim Care Community Health. 2016;7(1):41-3.

30. Singer SJ, Kerrissey M, Friedberg M, Phillips R. A Comprehensive Theory of Integration. Med Care Res Rev. 2018:1077558718767000.

31. Enthoven AC. Integrated delivery systems: the cure for fragmentation. Am J Manag Care. 2009;15(10 Suppl):S284-90.

32. Shaw SE, Rosen R. Fragmentation: a wicked problem with an integrated solution? J Health Serv Res Policy. 2013;18(1):61-4

33. Hwang W, Chang J, Laclair M, Paz H. Effects of integrated delivery system on cost and quality. Am J Manag Care. 2013;19(5):e175-84.

34. Coddington DC, Moore KD, Fischer EA. Costs and benefits of integrated healthcare systems. Healthc Financ Manage. 1994;48(3):20-4, 6, 8-9.

35. Enthoven AC. What is an Integrated Health Care Financing and Delivery System (IDS)? and What must would-be IDS Accomplish to Become Competitive with them? Health Econ Outcome Res Open Access. 2016;2(2).

36. Katerndahl D, Parchman M, Wood R. Perceived complexity of care, perceived autonomy, and career satisfaction among primary care physicians. J Am Board Fam Med. 2009;22(1):24-33.

37. Grembowski D, Ulrich CM, Paschane D, Diehr P, Katon W, Martin D, et al. Managed care and primary physician satisfaction. J Am Board Fam Pract. 2003; 16(5):383-93.

38. Vimalananda VG, Fincke BG, Gian S, Waring ME, Seibert RG, Meterko M. Development and psychometric assessment of a novel survey to measure care coordination from the specialist's perspective. Health Serv Res. 2019;54(3):689-99.

39. Veterans Health Administration. Restoring trust in Veterans health care. Fiscal year 2016 annual report. 2016. https://www.va.gov/HEALTH/ docs/VHA_AR16.pdf Accessed May 1, 2020.

40. Vimalananda VG, Meterko M, Gian S, Wormwood JB, Solch A, Fincke BG. A Survey to Measure Coordination of Specialty Care as Experienced by Primary Care Providers: Development and Psychometric Analysis of the CSC-PCP. Health Serv Res. Under Review.

41. Vimalananda VG, Meterko M, Waring ME, Gian S, Solch A, Wormwood JB, et al. Tools to improve referrals from primary care to specialty care. Am J Manag Care. 2019;25(8):e237-e42.

42. Vimalananda VG, Dvorin $\mathbf{K}$, Fincke BG, Tardiff N, Bokhour BG. Patient, Primary Care Provider, and Specialist Perspectives on Specialty Care Coordination in an Integrated Health Care System. J Ambul Care Manage. 2018;41(1):15-24.

43. Linsky A, Simon SR, Stolzmann K, Bokhour BG, Meterko M. Prescribers' perceptions of medication discontinuation: survey instrument development and validation. Am J Manag Care. 2016;22(11):74754.

44. Mohr DC, Benzer JK, Vimalananda VG, Singer SJ, Meterko M, McIntosh N, et al. Organizational Coordination and Patient Experiences of Specialty Care Integration. J Gen Intern Med. 2019;34(Suppl 1):30-6.

45. Glaser B, Strauss A. The Discovery of Grounded Theory. Chicago: Aldine; 1967.

46. Garcia J, Evans J, Reshaw M. "Is There Anything Else You Would Like to Tell Us" - Methodological Issues in the Use of Free-Text Comments from Postal Surveys. Quality \& Quantity. 2004;38:113-25.

47. O'Cathain A, Thomas KJ. "Any other comments?" Open questions on questionnaires - a bane or a bonus to research? BMC Med Res Methodol. 2004;4:25.

48. Coombe J, Harris ML, Loxton D. Motivators of contraceptive method change and implications for long-acting reversible contraception (nonJuse: A qualitative free-text analysis. Sex Reprod Healthc. 2019;19:71-7.

49. Setchell J, Leach LE, Watson BM, Hewett DG. Impact of Identity on Support for New Roles in Health Care. Journal of Language and Social Psychology. 2015;34(6):672-86.

50. Zuchowski JL, Rose DE, Hamilton AB, Stockdale SE, Meredith LS Yano EM, et al. Challenges in referral communication between VHA primary care and specialty care. J Gen Intern Med. 2015;30(3):305-11.

51. Linzer M, Konrad TR, Douglas J, McMurray JE, Pathman DE, Williams ES, et al. Managed care, time pressure, and physician job satisfaction: results from the physician worklife study. J Gen Intern Med. 2000;15(7):441-50.

52. Shanafelt TD, Sloan JA, Habermann TM. The well-being of physicians. Am J Med. 2003;114(6):513-9.

53. Shirom A, Nirel N, Vinokur AD. Overload, autonomy, and burnout as predictors of physicians' quality of care. J Occup Health Psychol. 2006; 11(4):328-42.

54. Bodenheimer T, Berenson RA, Rudolf P. The primary care-specialty income gap: why it matters. Ann Intern Med. 2007;146(4):301-6.

55. Patmas MA. Hospital-employed physician networks: are primary care physician undervalued? Physician Exec. 2010;36(6):12-4.

56. Norredam M, Album D. Prestige and its significance for medical specialties and diseases. Scand J Public Health. 2007;35(6):655-61.

57. Creed PA, Searle J, Rogers ME. Medical specialty prestige and lifestyle preferences for medical students. Soc Sci Med. 2010;71(6):1084-8.

58. Gibbons MC, Lowry SZ, Patterson ES. Applying Human Factors Principles to Mitigate Usability Issues Related to Embedded Assumptions in Health Information Technology Design. JMIR Hum Factors. 2014;1(1):e3.

59. Zahabi M, Kaber DB, Swangnetr M. Usability and Safety in Electronic Medical Records Interface Design: A Review of Recent Literature and Guideline Formulation. Hum Factors. 2015;57(5):805-34.

60. Yan C, Rose S, Rothberg MB, Mercer MB, Goodman K, Misra-Hebert AD. Physician, Scribe, and Patient Perspectives on Clinical Scribes in Primary Care. J Gen Intern Med. 2016;31(9):990-5.

61. Gidwani R, Nguyen C, Kofoed A, Carragee C, Rydel T, Nelligan I, et al. Impact of Scribes on Physician Satisfaction, Patient Satisfaction, and Charting Efficiency: A Randomized Controlled Trial. Ann Fam Med. 2017;15(5):427-33.

62. Kim LY, Rose DE, Soban LM, Stockdale SE, Meredith LS, Edwards ST, et al. Primary Care Tasks Associated with Provider Burnout: Findings from a Veterans Health Administration Survey. J Gen Intern Med. 2018;33(1):50-6.

63. Smith CD, Balatbat C, Corbridge S, Dopp AL, Fried J, Harter R, et al. Implementing optimal team-based care to reduce clinician burnout. Discussion paper. Natl Acad Med; 2018.

64. Gregory ME, Russo E, Singh H. Electronic Health Record Alert-Related Workload as a Predictor of Burnout in Primary Care Providers. Appl Clin Inform. 2017;8(3):686-97. 
65. Craig N, McGregor S, Drummond N, Fischbacher M, Iliffe S. Factors affecting the shift towards a 'primary care-led' NHS: a qualitative study. National Health Service. Br J Gen Pract. 2002;52(484):895-900.

66. Sampson R, Barbour R, Wilson P. The relationship between GPs and hospital consultants and the implications for patient care: a qualitative study. BMC Fam Pract. 2016;17:45.

67. Tuot DS, Leeds K, Murphy EJ, Sarkar U, Lyles CR, Mekonnen T, et al. Facilitators and barriers to implementing electronic referral and/or consultation systems: a qualitative study of 16 health organizations. BMC Health Serv Res. 2015;15:568.

68. Goodson JD. Unintended consequences of resource-based relative value scale reimbursement. JAMA. 2007;298(19):2308-10.

69. Conrad DA, Sales A, Liang SY, Chaudhuri A, Maynard C, Pieper L, et al. The impact of financial incentives on physician productivity in medical groups. Health Serv Res. 2002;37(4):885-906.

70. Tufano J, Conrad DA, Sales A, Maynard C, Noren J, Kezirian E, et al. Effects of compensation method on physician behaviors. Am J Manag Care. 2001;7(4):363-73.

71. Rose AJ. What We Aren`t Measuring Yet: Applying Quality Measurement More Broadly. J Gen Intern Med. 2016;31(8):821-2.

72. Gandhi TK, Sittig DF, Franklin M, Sussman AJ, Fairchild DG, Bates DW. Communication breakdown in the outpatient referral process. J Gen Intern Med. 2000;15(9):626-31.

73. O'Malley AS, Reschovsky JD. Referral and consultation communication between primary care and specialist physicians: finding common ground Arch Intern Med. 2011;171(1):56-65.
74. Mehrotra A, Forrest CB, Lin CY. Dropping the baton: specialty referrals in the United States. Milbank Q. 2011;89(1):39-68.

75. The Patient-Centered Medical Home Neighbor: The Interface of PatientCentered Medical Home with Specialty/Subspecialty Practices. A Policy Paper. Philadelphia: American College of Physicians; 2010.

76. Corley MC. Nurse moral distress: a proposed theory and research agenda. Nurs Ethics. 2002;9(6):636-50.

77. Kalvemark S, Hoglund AT, Hansson MG, Westerholm P, Arnetz B. Living with conflicts-ethical dilemmas and moral distress in the health care system. Soc Sci Med. 2004;58(6):1075-84.

78. Laabs CA. Moral problems and distress among nurse practitioners in primary care. J Am Acad Nurse Pract. 2005;17(2):76-84.

79. Armin JS. Administrative (in)Visibility of Patient Structural Vulnerability and the Hierarchy of Moral Distress among Health Care Staff. Med Anthropol Q. 2019;33(2):191-206.

80. Donelan K, DesRoches CM, Dittus RS, Buerhaus P. Perspectives of physicians and nurse practitioners on primary care practice. N Engl J Med. 2013;368(20):1898-906.

81. Buerhaus PI, DesRoches CM, Dittus R, Donelan K. Practice characteristics of primary care nurse practitioners and physicians. Nurs Outlook. 2015;63(2): 144-53.

82. Coplan B, Cawley J, Stoehr J. Physician assistants in primary care: trends and characteristics. Ann Fam Med. 2013;11(1):75-9.

Publisher's Note: Springer Nature remains neutral with regard to jurisdictional claims in published maps and institutional affiliations. 